\title{
Burden and Risk Factors of Chronic Kidney Disease in Children with Sickle Cell Anaemia Aged 5 - 16 Years at the University Teaching Hospital, Lusaka - Zambia
}

\author{
Machila $N^{1,2}$, Chabala $C^{1,2}$ Mwaba $C^{1,2}$, Chunda-C. L1, ${ }^{2}$
}

1. University Teaching Hospital, Department of Paediatrics and Child Health, P/B RW1X, Lusaka, Zambia

2. The University of Zambia, School of Medicine, Department of Paediatrics and Child Health, P.O. Box 50110, Lusaka, Zambia.

\section{Corresponding Author:}

Nchimunya Machila; University Teaching Hospital, Department of Paediatrics and Child Health, Private bag RW1X, Lusaka, Zambia. Telephone: +260977648587; E-mail address: nmachila@gmail.com

\begin{abstract}
Background: Improved medical care has led to the improved life expectancy of sickle cell anaemia (SCA) patients hence complications associated with SCA such as chronic kidney disease (CKD) are being seen more frequently. Globally, nephropathy of varying severity occurs in 5 to $18 \%$ of the SCA population across all age groups with a third of the adults proceeding to develop CKD while over 30 $\%$ of paediatric SCA patients have CKD in Africa. The mortality rate in SCA patients CKD is high. This study sought to determine CKD's prevalence and risk factors in SCA, which was not available in Zambia before this study. This information will guide targeting and timing of screening for CKD in SCA in children in our population.
\end{abstract}

Objectives: To determine the prevalence of haematuria, proteinuria, abnormal estimated glomerular filtration rate (eGFR), $\mathrm{CKD}$, and risk factors of CKD among the steady-state SCA patients aged 5 to 16 years at the University Teaching Hospital (UTH), Lusaka.

Methodology: This was a prospective crosssectional study of 197 children aged 5 to 16 years with SCA at the UTH - Lusaka conducted from August 2014 to July 2015. Demographic and clinical data were collected using a structured questionnaire. Urine and blood samples were used to determine the urine albumin creatinine ratio (ACR) and full blood count /blood biochemistry, respectively. CKD was defined and determined using the Kidney Disease Outcome Quality Initiative 2012 guidelines employing urine ACR, dipstick urinalysis and eGFR. In this study, spot urine ACR and dipstick urinalysis were done and repeated three months later if initial tests were abnormal.

Data was analysed using SPSS version 21. Chisquare and t-test were used to compare proportions between groups. The relation between study variables and CKD were examined using logistic regression.

Results: The mean age of the participants was 9.6 years $(\mathrm{SD} \pm 3.6)$. Male to female ratio was $1: 1$. The median age at diagnosis of SCA was 22 months $(\mathrm{IQR}=44)$. The prevalence of haematuria, proteinuria and CKD among the study participants was $14.2 \%, 36 \%$ and $36 \%$ respectively. Low haemoglobin and elevated mean corpuscular volume (MCV) were associated with CKD-AOR $0.62,95 \%$ CI; $0.46-0.84$ and $1.04,95 \%$ CI; 1.01 -1.08 , respectively. Recurrent admissions (due to VOCs, severe anaemia and febrile illness) were also risk factors associated with CKD- AOR 0.52, 95\% CI; 0.27-0.98. CKD was not associated with age at enrolment, sex, age at diagnosis of $\mathrm{SCA}$, recurrent Vaso-occlusive crisis (VOCs) or abnormal liver function tests.

Conclusion: The prevalence of CKD among the SCA patients at UTH- Lusaka is high (36\%) with lower haemoglobin, elevated MCV and recurrent admissions being risk factors for developing CKD. SCA patients should be screened for CKD routinely at least once a year. Interventions such as the early introduction of hydroxyurea, proactive blood transfusions, and ACE inhibitors can reduce CKD's risk and its progression to end-stage renal disease.

Keywords: Chronic kidney disease, sickle cell anaemia, nephropathy. 


\section{INTRODUCTION}

Sickle cell anaemia (SCA) is an autosomal recessive disease characterised by the inheritance of two abnormal genes coding for abnormal haemoglobin, of which both of them code for haemoglobin $\mathrm{S}^{(1)}$. Worldwide, 300,000 babies with sickle cell anaemia (SCA) are born. Sub-Saharan Africa accounts for $75 \%$ of sickle cell anaemia cases $^{(2)}$. Chronic and /or recurrent sickling of red blood cells (RBCs) underlies the mechanism of several complications of $\mathrm{SCA}^{(1,2)}$. Kidney injury due to recurrent sickling of RBCs predisposes to chronic kidney disease (CKD). Globally, nephropathy of varying severity occurs in 5 to $18 \%$ of the sickle cell population across all age groups $^{(2-4)}$.In the Middle East, North America and South America the prevalence of CKD in SCA is 5.1 to $26.5 \%\left({ }^{5-8)}\right.$ in contrast to what is prevailing in Sub-Saharan Africa in which the prevalence of CKD is as high as $68.4 \%$ across all age groups. Stratifying data further, up to $31.6 \%$ of paediatric SCA patients have CKD in Africa ${ }^{(9-11)}$.

In Zambia, there is a large cohort of patients with SCA on long-term follow up currently at the University Teaching Hospital (UTH) -Lusaka, yet the prevalence and risk factors of CKD among paediatric patients were not known before this study. This knowledge gap for clinicians affects the targeting and timing of screening for CKD in children with SCA. No definite treatment for CKD is available in our set up. Early screening and use of interventions such as the use of hydroxyurea and angiotensin-converting enzyme (ACE) inhibitors would enable slowed progression of SCA associated CKD. These have been shown to slow down the onset of CKD in SCA patients. This study sought to determine CKD's prevalence and risk factors in steady-state SCA patients aged 5 to 16 years at UTH - Lusaka. Findings from this study will thus form the basis for protocol formulation for targeted screening and interventions for diagnosis and slowing down of CKD in SCA patients, respectively.

\section{MATERIALS AND METHODS}

Study design: This was a prospective crosssectional study in known SCA anaemia patients at the UTH in Lusaka, Zambia. Data as collected between August 2014 and July 2015.

Study site: The study site was the emergency room and the haematology clinic in paediatrics and child health at the University Teaching Hospital (UTH) in Lusaka, Zambia.

Study population: Known SCA patients in a steady-state aged 5-16 years of age attending regular reviews at the haematology clinic and in the emergency room in the department of Paediatrics and Child Health at the UTH. Steady-state in sickle cell anaemia refers to a period between crises during which the patient is asymptomatic; usually, this period is four weeks or more.

\section{Inclusion and exclusion criteria:}

(a) Inclusion criteria: To be included in the study, the participants had to be sickle cell anaemia patients with $\mathrm{Hb} \mathrm{SS}$ electrophoresis results, aged 5-16 years, asymptomatic for at least four weeks, and parental/Guardian consent (with child assent where applicable) was a must

(b) Exclusion criteria: The prospective study participants were excluded from the study if one had a confirmed or suspected urinary tract infection. Pregnant patients or those patients having menses were not enrolled in the study

Sample size: Based on the estimated prevalence of $15 \%$ chronic kidney disease in SCA patients, 197 participants were enrolled in order to identify the true prevalence of CKD. The formula for prevalence studies used to calculate the sample required is $\mathrm{N}=\left[\mathrm{Z}^{2} \mathrm{XP}(1-\mathrm{P})\right] / \mathrm{E}^{2}$

Where $\mathrm{N}=$ sample required, $\mathrm{Z}=\mathrm{Z}$ statistic $=1.96$ (95 percent significance level), $\mathrm{P}=$ expected prevalence 0.15 [assuming a 15 percent prevalence of $\mathrm{CKD}$ in SCA patients $\left.{ }^{(2-4)}\right], \mathrm{E}=$ margin error of 5 percent

Therefore, $\mathrm{N}$ (sample required) $=\left[(1.96)^{2} \mathrm{X}\right.$ $0.15(1-0.15)] /(0.05)^{2}=196$.

Sampling method: Random sampling method was used to select patients that participated in this study.

Data collection: A structured questionnaire was used to collect socio-demographic details, medical history of study interest such as frequency of vaso-occlusive crises (VOCs), admissions and 
blood transfusions in the preceding one year, drug history and age at diagnosis of SCA. Laboratory forms were used to collect data for the laboratory in investigations.

Study procedure: After obtaining consent (and child assent where applicable), each of the enrolled participants had an intervieweradministered data collection questionnaire filled in. This questionnaire collected demographic data, past and current medical history after which physical examination and collection of specimens followed. Using the same study population, the questionnaire was piloted before being used for this study. The data collected from twenty study participants who were involved in the piloting of the study questionnaire formed part of the data for this study because no changes were made to the variables under study. Urine for dipstick urinalysis and urine albumin creatinine ratio (ACR) while blood-a total of 4 millilitres was drawn from each study participant for full blood count (FBC) and biochemistry analysis, i.e. urea, Creatinine (Cr), aspartate transaminase (AST) and alanine transaminase (ALT). The machine used for doing biochemistry is Pentra 400 made by Horiba ABX in France while FBC was done using XS 800i sysmex made in Japan in 2005. The study participants with proteinuria, haematuria and / or abnormal estimated glomerular filtration rate (eGFR) were reviewed at three months from the date of enrollment to repeat the urinalysis, urine ACR and / or calculation of eGFR to assess for the presence of CKD (As per study definition of CKDrefer to study definitions). The participants who became symptomatic, i.e. those who developed VOCs, febrile illnesses, urinary tract infections while waiting for the three months to come for review for purposes of this study had to be reenrolled into the study after being asymptomatic for four weeks.

\section{Study Definitions:}

(i) Proteinuria: The presence of proteins in urine. Proteinuria of $1+$ or more on dipstick urinalysis and/ or microalbuminuria on urine ACR constituted an outcome of proteinuria.

(ii) Haematuria: Presence of blood in the urine. Haematuria of $1+$ or more constituted haematuria on dipstick urinalysis. (iii) Abnormal eGFR: eGFR less than $60 \mathrm{~mL} /$ $\mathrm{min} / 1.73 \mathrm{~m}^{2}$ (calculated using updated Schwartz formula) constituted an abnormal eGFR based on the 2012 KDIGO guidelines

(iv) CKD: The presence of one or more of the above-mentioned primary outcomes for a minimum period of three months constituted an outcome ofCKD. To determine the presence of CKD, all participants with proteinuria, haematuria and / or abnormal eGFR were reassessed for the persistence of proteinuria, haematuria and / or abnormal eGFR at three months after the initial assessment.

Data management: A standardised data questionnaire for each participant was used for data collection, and codes identified participants to ensure anonymity. Data was stored in a lockable cabinet with the principal investigator having sole access to the lockable cabinet. The data was entered on the Epidata software with double-entry being performed to reduce human errors.

Data analysis: Data were analysed using the statistical software package SPSS version 21. All statistical tests were at 5\% significance level. The Independent Samples T-test was used to compare mean values between groups while Pearson's chisquared was used to compare proportions between groups. The relationship between study variables and the outcome variable of interest (CKD) was examined using multiple logistic regression. Selection for the logistic regression model was considered at level $\mathrm{P}<0.20$ or known clinical significance. Backward selection method was used to obtain the final logistic regression model. The backward selection method removes terms one at a time beginning with the largest p-value and continuing until all remaining effects are significant at a specified level or removing more terms results in poorer fit.

Ethical considerations: Before the study was carried out, ethical approval and permission were obtained from the research ethics committee (ERES CONVERGE IRB) and the study site, respectively. The purpose of the study was explained to the parents/guardians and participants. It was emphasised that participation in this study was purely voluntary, with no financial rewards 
or gains for taking part in this study. Consent was sought from parents/guardians (and child assent from participants where applicable).

\section{RESULTS}

A total number of 197 study participants was enrolled and considered in the final analysis. The response rate was about $92 \%$.

\section{Descriptive Demographic and Clinical Characteristics}

The participants' mean age was 9.55 years ( standard deviation $= \pm 3.356$ )-see figure 1 , which shows the age distribution histogram. The male to female ratio was $1: 1$, as shown in table 1 . All the study participants were of African origin. About $92 \%$ were underweight with body mass index $(\mathrm{BMI})<18.5 \mathrm{Kg} / \mathrm{m}^{2}$. The median age at diagnosis of SCA was 22 months (interquartile range was 44 months). The median age at diagnosis of SCA for females versus males was 18 months and 24 months, respectively. The difference was not statistically significant.

\section{Prevalence of CKD among the study participants}

The prevalence of CKD among the study participants was found to be $36 \%$, i.e. 71 study participants fulfilled the study definition of CKD, and these had persistent proteinuria and / or haematuria as illustrated in figure 2 .

\section{Prevalence of proteinuria and Haematuria in SCA}

Seventy-one participants (36\%) of the participants had persistent proteinuria as determined by use of dipstick urinalysis and urine ACR. This study found that $28(14.2 \%)$ of the participants with persistent haematuria see figure 2 .

\section{Prevalence of abnormal eGFR}

No study participant was found to have an eGFR below $60 \mathrm{~mL} / \mathrm{min} / 1.73 \mathrm{~m}^{2}$. Actually, 81 percent (160) of the study participants had eGFR levels higher than normal, with the average eGFR being $181.6 \mathrm{~mL} / \mathrm{min} / 1.73 \mathrm{~m}^{2}(\mathrm{SD}= \pm 34.36)$.

\section{Risk factors of CKD in SCA}

Multiple logistic regression analysis was conducted to identify independent factors associated with CKD. Age at diagnosis, haemoglobin ( $\mathrm{Hb})$, platelets count, mean corpuscular volume (MCV), urea, and hospital admission status were entered into a multiple logistic regression model, and the backward selection method applied. Adjusting for $\mathrm{Hb}$ and $\mathrm{MCV}$, children with no history of admission record in the past one year had on average $49 \%$ reduced odds for CKD [Odds Ratio $(\mathrm{OR})=0.51,95 \%$ Confidence Interval $(\mathrm{CI})=0.27$ - 0.96, P-value $=0.04]$. Adjusting for admission status and MCV, for every 1 unit increase in $\mathrm{Hb}$, the odds for CKD on average reduced by $38 \%$ (OR $=0.61, \mathrm{CI}=0.45-0.83, \mathrm{P}$-value $<0.01)$. Adjusting for admission status and $\mathrm{Hb}$, for every increase of 1 unit in MCV the odds for CKD increased on average by about $4 \%(\mathrm{OR}=1.04, \mathrm{CI}=1.01-1.08$, $\mathrm{P}$-value $=0.01)$. Statistical evaluation of the risk factors is shown in tables 1, 2 and 3.

\section{DISCUSSION}

\section{Prevalence of CKD}

A prevalence of CKD of $36 \%$ was found among the SCA paediatric population at UTH. This high prevalence of CKD falls within the range of 5.1 to $68.4 \%$ found in various studies across the sickle cell populations in low-income countries and is much similar to what was found in the Ghanaian study which found a prevalence of CKD among sickle cell patients to be $31.6 \%$ in the paediatric age group $^{(5,7,10,11)}$. In Zambia, there is a high disease burden of sickle cell, poor health services, late diagnosis SCA and poor health-seeking behaviour, leading to a significant prevalence of CKD among the SCA population.

\section{Prevalence of proteinuria}

Persistent proteinuria was present in $36 \%$ of the study participants. This is similar to findings of two earlier studies done at UTH, which reported a prevalence of up to 41 percent, predominantly enrolled participants outside the paediatric age group $^{(12,13)}$. These findings are comparable with various studies in several parts of the world, ranging from 15.9 to $41 \%$ in areas such as the USA, Saudi Arabia, West and Eastern African

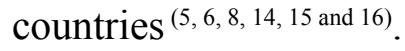

\section{Prevalence of Haematuria}

Persistent haematuria was present in 14.2 percent of the study participants, and this prevalence is comparable with 13 percent reported in three 
studies in Saudi Arabia, Ghana and Tanzania done in the paediatric population age group, respectively. However, the prevalence of haematuria in this study was significantly lower than in two earlier studies done at UTH-Lusaka which demonstrated a prevalence of haematuria ranging from 32 to 92 $\%$ among sickle cell patients ${ }^{(12,13)}$. The variations in study population profile could explain this difference with the latter. The earlier studies done at UTH-Lusaka recruited a population with a bias towards adults; hence a higher prevalence of haematuria as SCA associated complications is common in adults.

\section{Abnormal eGFR}

No study participant was found to have a belownormal eGFR. However, $81 \%$ of the study participant had hyperfiltration, a finding known to occur frequently in SCA and similar to what was found in studies done in Brazil, Saudi Arabia and the USA which showed hyperfiltration of up to $76 \%$ among sickle cell patients ${ }^{(5,7,15)}$.

\section{Risk factors of CKD in SCA}

Evaluation of various risk factors for CKD in SCAidentified three risk factors associated with CKD in SCA in this study. Low haemoglobin and elevated MCV were risk factors associated with CKD. Low haemoglobin is a risk factor for CKD, as documented in the literature by a USA study (8). High MCV in SCA is usually a result of folate deficiency, and this, in turn, causes megaloblastic anaemia. The finding, in this study, that increased MCV above the normal is a risk factor for CKD can be explained by the fact that folate deficiency causes anaemia, which in turn predisposes to CKD, as anaemia is a risk factor for CKD, a finding similar and in agreement with what is already published by various studies $(4,7,8)$ Thus, poor adherence to daily folate prophylaxis can result in megaloblastic anaemia that predisposes to CKD.

In this study, there was no association between recurrent VOCs (on their own) and CKD (P-value $>0.05)$, which is contrary to what is expected and known. The possible reason for lack of association between recurrent VOCs and CKD in this study could be possible poor recall by patients or caregivers of VOC events because caregivers could have changed or VOCs were mild and did not require hospital admission/attention. History of recurrent admissions was a risk factor for CKD, and this is because the causes of admissions were a combination of anaemia, VOCs and febrile illness. These are interrelated, and all eventually lead to hypoxia, which leads to SCA associated complications, including CKD.

Blood transfusions did not confer any protection against $\mathrm{CKD}$ in this study $(\mathrm{P}>0.05)$, this is consistent with findings of a study done in the USA in which chronic blood transfusion did not offer protection against CKD in sickle cell patients ${ }^{(8)}$. Those who received blood transfusions may have already developed CKD before the blood transfusions, or probably they did not receive an adequate number of blood transfusions for the latter to be protective against CKD. It is be expected that regular blood transfusions would reduce the concentration of RBCs with $\mathrm{HbSS}$ hence reducing the risk for SCA associated complications such as recurrent VOCs, severe anaemia and spleen sequestration of RBCs. This, in turn, may result in a low frequency of recurrent hypoxia leading to a reduced risk of end-organ damage and problems such as CKD.

\section{Main challenges}

The data obtained from this research may not reflect the true picture in sickle cell anaemia patients seen at local clinics within Lusaka because patients with the most severe complications are usually found at the UTH most of the times. The Schwartz formula used to calculate the eGFR, though validated for use in children, is known to overestimate the eGFR by as much as $45 \mathrm{~mL} / \mathrm{min} / 1.73 \mathrm{~m}^{2}$ hence the values of eGFR may not be a true reflection of the actual GFR. Of the available formulae, alternative formulae will still overestimate the eGFR and are yet to be validated in children. Though functional abnormalities accompany structural abnormalities leading to $\mathrm{CKD}$, structural abnormalities were not identified as no abdominal ultrasounds were done due to lack of certified manpower to carry out this test. Therefore, this vital information was not obtained.

\section{CONCLUSION}

The prevalence of CKD, proteinuria and haematuria among the SCA patients at the UTH- Lusaka, is high (36\%). Low haemoglobin, elevated MCV and history of recurrent admissions (due to VOCs, 
severe anaemia and febrile illness) are risk factors for developing CKD. Blood transfusions do not seem to offer protection against CKD development in SCA. Age at diagnosis of SCA, recurrent VOCs (on their own), abnormal LFTs, sex, low BMI, thrombocytosis is not associated with CKD in SCA. SCA patients should be screened routinely for renal dysfunction from the age of two years at least once a year using measures such as dipstick urinalysis, urine ACR, determination of eGFR, routine $\mathrm{BP}$ measurement and abdominal ultrasound

\section{ACKNOWLEDGEMENTS}

We are indebted to the University Teaching Hospital management for the permission to use their laboratories and the staff of Paediatrics department laboratories for their reliability, professionalism and willing cooperation. We acknowledge the effort of the research assistants Patricia and Jolezya Mudenda and the nurses and clerks in the haematology clinic and emergency room in the Department of Paediatrics and Child Health. Lastly, we are highly indebted to the study participants and their parents or guardians for their willingness to participate in the study.

\section{REFERENCES}

1 DeBaun MR and Vichinsky E.Nelsons textbook of the paediatrics $18^{\text {th }}$ edition (2007), Saunders, an imprint of Elsevier Inc.

2 Makani J, Ofori-AcquahSF, Nnodu O, Wonkam A and Ohene-Frempong K. Sickle cell disease: New opportunities and challenges for Africa. The scientific world journal, Volume 2013, Article ID 193252, pages 1 -16.

3 Scheinmann JI: Sickle cell nephropathy. Pediatric Nephrology, edited by Holliday M, Barratt TM, Avner ED, Baltimore, Williams \& Wilkins, 1994, pages 908-919.

4 Powers DR, Elliot-Mills MDD, Chan L, Hiti AL, Opas LM and Johnson C. Chronic renal failure in sickle cell disease, Risk factors, clinical course and mortality, Ann Intern Med 115: 614-620, 1991.

5 Aleem A. Renal abnormalities in patients with sickle cell disease: a single-centre report from Saudi Arabia. Saudi J Kidney Dis Transpl 2008; 19(2): 194-199.

6 Bodas P, Huang A, O'Riordan AN, Sedor JR and $\mathrm{KD}$. The prevalence of hypertension and abnormal kidney function in children with sickle cell disease- a cross-sectional review Nephrology 2013, 14: 237. http://www. biomedcentral.com/1471-2369/14/237

7 Silva Junior GB, Liborio AB, Viera APF, ACX Bem, Filho ASL, ACF Filho et al. Evaluation of renal function in sickle cell disease in Brazil, Brazilian Journal of medical and Biological research (2012) b45: $652-655$.

8 Yee MM, Jabbar SF, Osunkwo I Clement L, Lane PA, Eckman JR et al. Chronic kidney disease and albuminuria in children with sickle cell disease. Clin J Am SOC Nephrol 6: 2628- 2633, 2011.

9 Aneke JC, Adegoke AO, Oyekunle AA et al, degrees of kidney disease in Nigerian adults with Sickle cell disease, medical principle and practice 2014;23:271-274, DOI: 10.1159/000361029

10 Madu AJ, A Ubesie, Ocheni S, Chinawa J, Madu KA, Ibegbulam OG et al. Important clinical and laboratory correlates of glomerular filtration rate in sickle cell anaemia, Nigerian Journal of clinical practice, Sep-Oct 2015. Volume 18. Issue 5.

11 Ephraim RKD, Osakunor DNM and Cudjoe $\mathrm{O}$, Oduro EA, Asante-Asamani, Mitchell $\mathrm{J}$ et al, Chronic kidney disease is common in sickle cell disease: a cross-sectional study in the Tema Metropolis, Ghana, BMC Nephrology (2015) 16:75, DOI 10.1186/s12882-0150072-y

12 Chansa C. Prevalence of Iron deficiency anaemia in adult patients with sickle cell anaemia at the University Teaching Hospital in Lusaka, Zambia. Dissertation study, March 2012.

13 Musonda C. Renal abnormalities among sickle cell anaemia patients aged ten years and above at the University Teaching Hospital, Lusaka, Zambia. Dissertation study, 2010.

14 Alleyne GAO, Statius van Eps LW and Addac SK: The kidney in sickle cell anaemia. (editorial review) Kidney Int 7:371-379, 1975.

15 Aygun B, Mortier NA, Smeltzer MP, Hankins JS, and Ware RE. Glomerular hyperfiltration and albuminuria in children with sickle cell anaemia. Pediatr Nephrol (2011) 26: 12851290.

16 Guash A, Cua M and You W. Sickle cell anaemia causes a distinct pattern of glomerular dysfunction. Kidney int 1997: 51: 826-33. 


\section{TABLES AND FIGURES FOR THE STUDY DATA ANALYSIS}

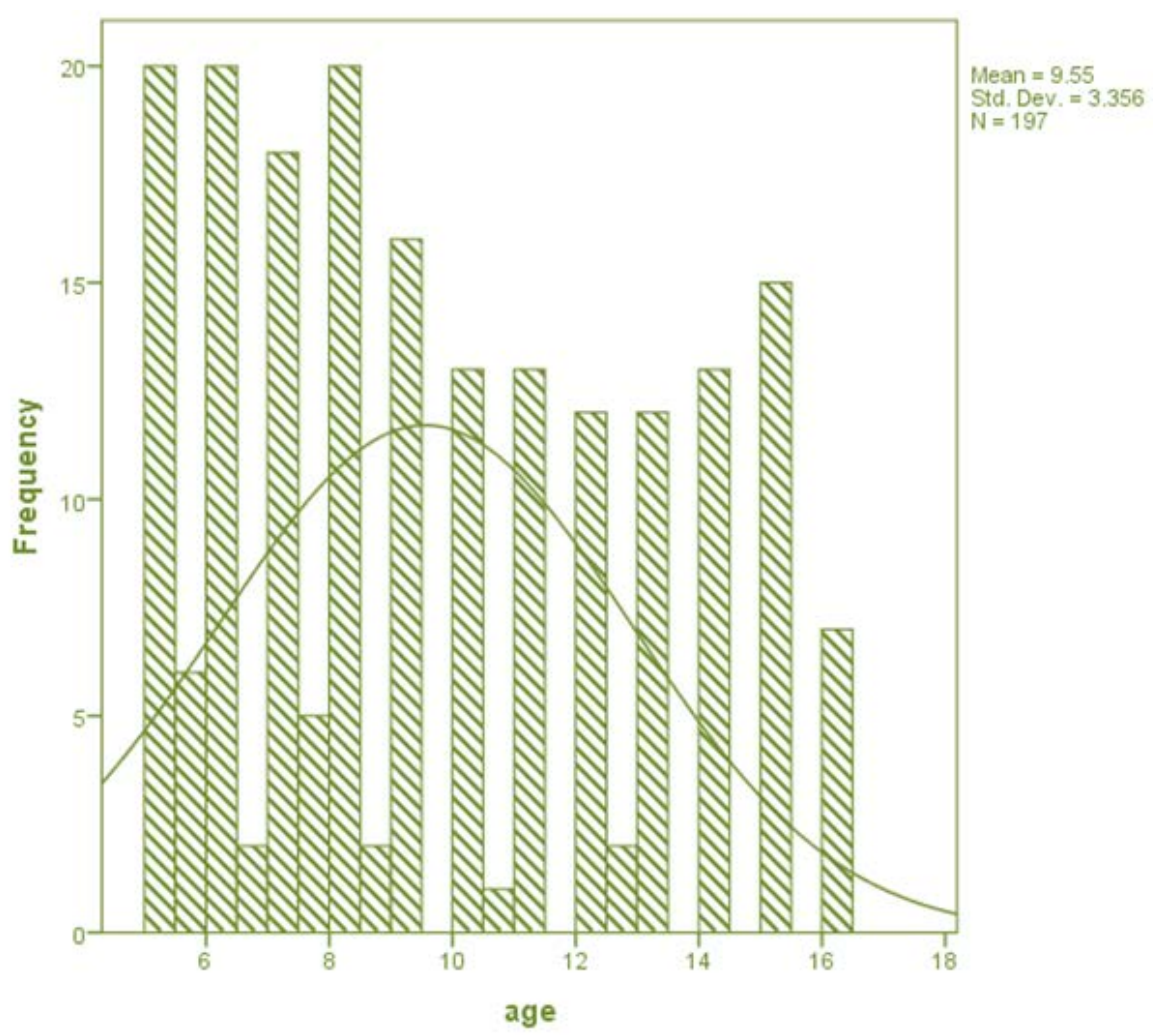

Figure 1: Age distribution of study participants

\begin{tabular}{|l|l|}
\hline \multicolumn{1}{|c|}{ Variable } & \multicolumn{1}{c|}{ Result } \\
\hline Age at enrolment in years & Mean age $=9.55$ years(SD: 3.356) \\
\hline Median age at diagnosis of SCA & 22 months (IQR -44$)$ \\
\hline Sex & Male - 99 $(50.3 \%)$ \\
\hline & Female - 98(49.7\%) \\
\hline Race & Female to male ratio - 1:1 \\
\hline BMI & $197(100 \%)$ were of African decent \\
\hline HIV status & $\begin{array}{l}182(92.4 \%) \text { were underweight } \\
15(7.6 \%) \text { had a normal BMI }\end{array}$ \\
\hline Drug History & $197(100 \%)$ participants were HIV negative \\
\hline Participants transfused in the proceeding one year & $81(41 \%)$ had at least one blood transfusion \\
\hline $\begin{array}{l}\text { Participants affected by VOCs in the proceeding } \\
\text { one year. }\end{array}$ & $\begin{array}{l}182(93 \%) \text { were on deltaprim and folate } \\
45(7 \%) \text { were on hydroxyurea, deltaprim and folate }\end{array}$ \\
\hline Frequency of admissions & $68(34.5 \%)$ had 2 or more admissions \\
\hline
\end{tabular}




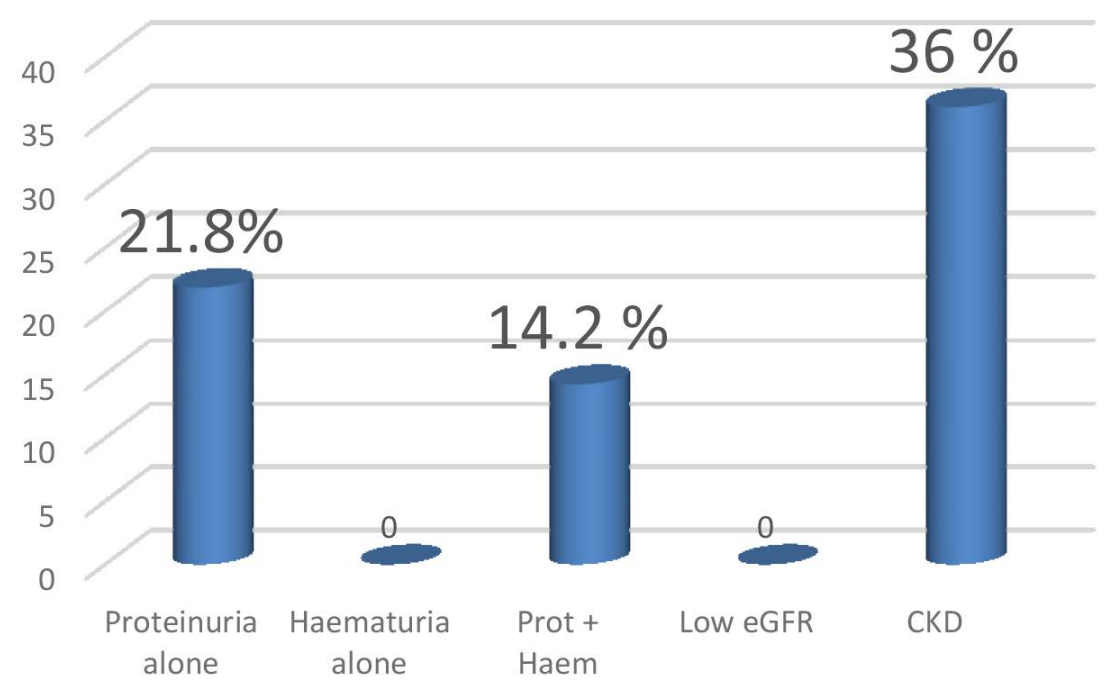

Figure 2. Frequency of Primary outcomes (\%)

Participant had eGFR less than $60 \mathrm{~mL} / 1.73 \mathrm{~m} 2 / \mathrm{min}$ or haematuria alone

\begin{tabular}{|c|c|c|c|c|c|}
\hline \multirow[t]{2}{*}{ VARIABLE } & \multicolumn{2}{|c|}{ CKD ABSENT $(n=126)$} & \multicolumn{2}{|c|}{ CKD PRESENT $(n=71)$} & \multirow[t]{2}{*}{ P-VALUE } \\
\hline & $\mathbf{N}$ & $\%$ & $\mathbf{N}$ & $\%$ & \\
\hline \multicolumn{6}{|l|}{ Age group: } \\
\hline $5-9$ years & 72 & $57.10 \%$ & 37 & $52.10 \%$ & 0.50 \\
\hline $10-16$ years & 54 & $42.90 \%$ & 34 & $47.90 \%$ & \\
\hline \multicolumn{6}{|l|}{ Sex: } \\
\hline Male & 65 & $51.60 \%$ & 34 & $47.90 \%$ & 0.62 \\
\hline Female & 61 & $48.40 \%$ & 37 & $52.10 \%$ & \\
\hline \multicolumn{6}{|l|}{ Blood Transfusion: } \\
\hline No & 71 & $56.30 \%$ & 45 & $63.40 \%$ & 0.34 \\
\hline Yes & 55 & $43.70 \%$ & 26 & $36.60 \%$ & \\
\hline \multicolumn{6}{|l|}{ VOC: } \\
\hline No & 29 & $23.00 \%$ & 22 & $31.00 \%$ & 0.22 \\
\hline Yes & 97 & $77.00 \%$ & 49 & $69.00 \%$ & \\
\hline \multicolumn{6}{|l|}{ Admission in the past one year: } \\
\hline No & 40 & $31.70 \%$ & 32 & $45.10 \%$ & 0.06 \\
\hline Yes & 86 & $68.30 \%$ & 39 & $54.90 \%$ & \\
\hline \multicolumn{6}{|l|}{ BMI: } \\
\hline Underweight $(<18.5)$ & 115 & $91.30 \%$ & 67 & $94.40 \%$ & 0.43 \\
\hline Normal weight (18.5 - 24.9) & 11 & $8.70 \%$ & 4 & $5.60 \%$ & \\
\hline
\end{tabular}

There was no association between age group, sex, blood transfusion, VOC, BMI, age at diagnosis and CKD. 
Table 3: Bivariate analysis for continuous variables using t-test

\begin{tabular}{|l|c|c|c|}
\hline Variable & CKD ABSENT (n= 126) & CKD PRESENT (n= 71) & P-value \\
\hline & Mean $($ SD) & Mean (SD) & \\
\hline Age at enrolment in years & $9.4(3.33)$ & $9.8(3.42)$ & 0.54 \\
\hline Age at diagnosis in months & $35.2(31.85)$ & $29.5(26.58)$ & 0.20 \\
\hline Weight & $25.8(9.84)$ & $25.7(8.04)$ & 0.96 \\
\hline Height & $125.2(15.14)$ & $126.3(16.65)$ & 0.65 \\
\hline BMI & $15.7(1.80)$ & $15.7(1.56)$ & 0.97 \\
\hline Hb & $7.6(1.25)$ & $7.1(1.07)$ & $<0.01$ \\
\hline Platelets & $432.1(137.67)$ & $400.4(143.0)$ & 0.13 \\
\hline WBC & $13.9(4.61)$ & $14.3(3.83)$ & 0.59 \\
\hline MCV & $79.3(9.91)$ & $83.0(9.94)$ & 0.01 \\
\hline ALT & $24.6(11.65)$ & $24.1(11.85)$ & 0.78 \\
\hline AST & $44.3(26.46)$ & $44.4(21.22)$ & 0.98 \\
\hline ALB & $41.9(5.57)$ & $41.6(4.85)$ & 0.72 \\
\hline
\end{tabular}

Severe anaemia and higher MCV were associated with CKD (P-value $<0.01$ and 0.01 , respectively).

Table 4: Logistic regression analysis predicting CKD

\begin{tabular}{|l|l|l|l|}
\hline Variable & \multicolumn{1}{|c|}{$\begin{array}{c}\text { Crude Odds Ratio } \\
(95 \% \mathrm{CI})\end{array}$} & $\begin{array}{c}\text { Adjusted Odds Ratio } \\
(95 \% \mathrm{CI})\end{array}$ & P-value \\
\hline \multicolumn{4}{|l|}{ Admission in the past one year: } \\
\hline Yes & 1 & 1 & 0.04 \\
\hline No & $0.57(0.31-1.03)$ & $0.52(0.27-0.98)$ & $<0.01$ \\
\hline Low Hb & $0.64(0.48-0.85)$ & $0.62(0.46-0.84)$ & 0.01 \\
\hline High MCV & $1.04(1.01-1.07)$ & $1.04(1.01-1.08)$ & \\
\hline
\end{tabular}

